\title{
Planejamento do Turismo Religioso e seus Desafios em Lunardelli, Vale do Ivaí, Paraná
}

\section{Religious Tourism Planning and its Challenges in Lunardelli, Vale do Ivaí, Paraná, Brazil}

\author{
Fabiane de Oliveira Domingos ${ }^{1}$ \\ Alini Nunes de Oliveira ${ }^{2}$ \\ Tatiana Colasante ${ }^{3}$
}

\begin{abstract}
Resumo - O Vale do Ivaí é uma região localizada no centro-norte paranaense, caracterizada pela presença de vários atrativos e potenciais para o turismo, dos quais se destacam os segmentos do turismo rural, aventura e religioso. É uma das regiões mais pobres do estado, por apresentar baixo Índice de Desenvolvimento Humano (IDH), apesar de importante atividade agrícola. Dentre os 26 municípios que fazem parte do Vale do Ivaí, destaca-se Lunardelli que recebe entre 100 e 250 mil visitantes por ano em decorrência do Santuário Santa Rita de Cássia, reconhecida na religião católica como a santa das causas impossíveis. A partir desse contexto, o objetivo da presente pesquisa foi analisar os principais desafios do planejamento do turismo religioso em Lunardelli dentro de um contexto de desenvolvimento local e regional. Optou-se pela pesquisa exploratória e qualitativa e direcionada a um estudo de caso para compreender melhor o desenvolvimento do turismo no município. Na questão teórica, utilizou-se de pesquisa bibliográfica e documental e para colaborar com a parte empírica, foram realizadas entrevistas semiestruturadas e visitas a campo. Como resultado, constatou-se que um dos maiores desafios do poder público local é potencializar o turismo de modo sustentável, com a geração de emprego e renda.
\end{abstract}

Palavras-chave: Turismo Religioso. Planejamento. Vale do Ivaí. Lunardelli.

\footnotetext{
${ }^{1}$ Doutorado em Geografia pela Universidade Estadual de Londrina. Mestrado em Geografia, Meio Ambiente e Desenvolvimento pela Universidade Estadual de Londrina. Graduação em Turismo e Hotelaria pela Universidade Norte do Paraná. Professora adjunta do Curso de Turismo e Negócios da Universidade Estadual do Paraná, Campus Apucarana. E-mail: fabianedomingos@hotmail.com

2 Doutorado em Geografia pela Universidade Estadual de Londrina. Mestrado em Geografia pela Universidade Estadual de Londrina. Graduação em Geografia pela Universidade Estadual de Londrina. Graduação em Turismo e Hotelaria pela Universidade Norte do Paraná. Pós-doutoranda em Turismo pela Universidade Federal do Paraná. E-mail: alini_nunes@hotmail.com

${ }^{3}$ Doutorado em Geografia pela Universidade Estadual Paulista, Campus Presidente Prudente. Mestrado em Geografia pela Universidade Estadual de Londrina. Graduação em Turismo e Hotelaria pela Universidade Norte do Paraná. Graduação em Geografia pela Universidade Estadual de Londrina. Professora Adjunta do Curso de Turismo da Universidade Federal do Maranhão campus São Bernardo. E-mail: tatiana.colasante@ufma.br
} 


\begin{abstract}
Vale do Ivaí is a region located in the north central of Paraná State, Brazil, characterized by several attractions and potential for tourism, from which it is highlighted the rural, adventure and religious tourism segments. At the same time, it is one of the poorest regions in the state due to its low Human Development Index (HDI), despite its important agricultural activity. Among the 26 municipalities that are part of the Vale do Ivaí Region, Lunardelli stands out because it receives from 100 to 250 thousand visitors per year due to the Santa Rita de Cássia Sanctuary, recognized in the Catholicism as being the saint of impossible causes. In this context, this research aimed to analyze the main challenges of planning the religious tourism in Lunardelli within a context of local and regional development. This study can be considered an exploratory and qualitative research oriented to a case study in order to better understand the development of tourism in this city. The theoretical framework is supported by a bibliographical and documentary research and regarding the empirical part, semi-structured interviews and fieldwork were carried out. As a result, it was found that one of the main challenges for the local public authorities is to make the tourism and structure grow in a sustainable way, with the creation of jobs and increase of local and regional income.
\end{abstract}

Keywords: Religious Tourism. Planning. Vale do Ivaí. Lunardelli. 


\section{INTRODUÇÃO}

A escolha de pesquisar o turismo religioso no município de Lunardelli para entender os desafios do planejamento da atividade turística, teve origem na tese de doutorado de uma das autoras, intitulada 'A política de regionalização do turismo no Vale do Ivaí: uma análise a partir do conceito de desenvolvimento regional' (DOMINGOS, 2018). Nessa pesquisa foi identificada que a região apresenta potencial para alguns segmentos de turismo como o rural, de aventura e principalmente o religioso. $\mathrm{O}$ turismo religioso no Vale do Ivaí ocorre pela forte influência da religião católica, devido a sua colonização, por meio de monumentos culturais e templos religiosos. Domingos (2018, p. 52) ressalta que:

O turismo de massa já é uma realidade observada em um dos municípios do Vale do Ivaí, Lunardelli. Este vem a cada ano recebendo mais visitantes no Santuário de Santa Rita de Cássia. Atualmente, a preocupação do Secretário de Turismo é a de fazer esse fluxo intenso de pessoas se converter em geração de emprego e renda, já que o município praticamente não dispõe de meios de hospedagem e o artesanato não é produzido pela comunidade local, para citar um dos problemas.

Além disso, mais alguns fatores foram considerados para a escolha do estudo como pelo fato do Vale do Ivaí ser uma das mais novas regiões turísticas criadas pelo estado do Paraná. Também é a região em que se localiza um dos poucos cursos de turismo no estado, ofertado pela Universidade Estadual do Paraná (UNESPAR), campus Apucarana. Outro fator se deve pela pouca existência de pesquisas sobre o turismo na região e por fim é uma região que apresenta vulnerabilidade econômica, social e ambiental.

No caso específico de Lunardelli, a escolha pelo recorte espacial se justificou por ser um dos municípios que mais recebe visitantes na região do Vale do Ivaí, o que gera vários impactos socioeconômicos e ambientais tanto positivos como negativos. Isso requer da universidade, interação com a região em que está inserida por meio de seus diversos agentes sociais. Essa interação é possibilitada quando a universidade se encontra mais próxima do governo e do mercado, assumindo maior responsabilidade diante das necessidades nacionais e regionais (DOMINGOS, 2018).

Houve uma demanda por estudos relacionados ao turismo em Lunardelli por parte do secretário de turismo, que há anos vinha tentando parcerias com o curso de turismo da 
UNESPAR Campus Apucarana. Mas foi somente em 2019 que esta parceria se consolidou a partir de uma das pesquisadoras do presente artigo, que é docente na universidade. Fruto da tese de doutorado da pesquisadora, foi criado um projeto de pesquisa intitulado "Planejamento do turismo religioso em Lunardelli no Vale do Ivaí, Paraná" em execução desde fevereiro de 2019. Uma das ações é a elaboração do Inventário da Oferta Turística do município a ser entregue em 2020.

Quanto à metodologia empreendida, trata-se de uma pesquisa exploratória de caráter qualitativo com a finalidade principal de desenvolver, esclarecer e modificar conceitos e ideias com vistas à formulação de problemas mais precisos ou hipóteses pesquisáveis para estudos posteriores (GIL, 2009). A partir de um estudo de caso, foi possível a análise holística que considera a unidade social estudada como um todo, com o objetivo de compreendê-la. Com isso, escolheu-se o município de Lunardelli pela sua dinâmica turística no Vale do Ivaí.

Para o embasamento teórico, foi realizada pesquisa bibliográfica e documental. A pesquisa bibliográfica, de acordo com Gil (2009), é desenvolvida a partir de material já elaborado, como livros e artigos científicos com contribuição de diversos autores sobre determinado assunto. Foram privilegiadas consultas a temas de planejamento do turismo, turismo religioso, desenvolvimento regional, geografia e turismo.

A pesquisa de campo ocorreu em 2018 e 2019 com o objetivo de coletar dados e observação in loco. Foi aplicada uma entrevista semiestruturada no dia um de agosto de 2018 com o secretário municipal de turismo Francisco Izidoro, sendo gravada com autorização do informante, com assinatura de um Termo de Consentimento Livre e Esclarecido. Posteriormente, a entrevista foi transcrita na íntegra para análise. A entrevista ocorreu para elaboração da tese de doutoramento de uma das autoras, conforme mencionado anteriormente. Naquele momento as 30 perguntas tinham como foco principal compreender o turismo a partir da ótica de desenvolvimento regional, ou seja, em relação ao Vale do Ivaí.

No dia 17 de março de 2019, uma das autoras esteve em Lunardelli acompanhada de alguns acadêmicos do Curso de Turismo da UNESPAR campus Apucarana. O objetivo foi o de realizar uma visita técnica no Santuário de Santa Rita de Cássia e outros equipamentos de turismo, como restaurantes. Durante a visita, o secretário municipal de 
turismo abordou diversos assuntos relacionados ao planejamento do turismo religioso sendo utilizadas nesse artigo para discussão de alguns temas.

Essa data foi escolhida por ser um domingo, dia de maior movimentação de visitantes no santuário de Santa Rida de Cássia. A partir das questões levantadas pelos alunos, o secretário municipal de turismo fez uma explanação sobre o turismo no município apresentando mais detalhes sobre a atividade, os principais problemas e projetos para a atividade.

A partir da metodologia exposta foi possível cumprir o objetivo central da pesquisa que é analisar os principais desafios do planejamento do turismo religioso em Lunardelli dentro de um contexto de desenvolvimento local e regional.

O trabalho foi estruturado iniciando a discussão sobre as concepções de planejamento e desenvolvimento e sua importância para o turismo. Em seguida, há uma contextualização do turismo religioso, explicitando as diferenças entre peregrinação e romaria. Então são apresentados os casos do município de Lunardelli, pontuando-se as características socioeconômicas e a evolução do turismo religioso na localidade, seguido dos resultados obtidos a partir das entrevistas realizadas e observação de campo. A partir dos resultados são expostas as considerações finais.

\section{O PLANEJAMENTO PARA O DESENVOLVIMENTO DO TURISMO RELIGIOSO}

Em face ao seu desenvolvimento, que envolve múltiplos fatores como sociais, econômicos, políticos, culturais e ambientais, é necessário pensar o turismo de forma ordenada e planejada com vistas à interação dos diferentes atores, privilegiando os interesses da comunidade local. De acordo com Faissol (1989, p. 194), “[...] o planejamento deve iniciar de baixo para cima, a partir da comunidade para unidades políticas e sociais mais amplas". O planejamento deve ser implantado para um número limite de atividades e por certo período.

Para Binfaré et al. (2016, p. 30), o “[...] planejamento é a organização sistemática de um conjunto de ideias e decisões, de forma integrada". Trata-se de uma ação voltada para o futuro e que demanda uma série de etapas que envolve desde a caracterização da área a ser estudada, inventariação até a implantação de planos para a execução das 
atividades propostas para dada realidade. Os autores enfatizam que quanto mais abrangente for o planejamento, mais complexo se torna, devido ao aumento das variáveis envolvidas. Assim, um planejamento municipal seria muito mais simplificado do que um planejamento regional, por exemplo.

Quanto ao papel dos planejadores no processo de formular e pensar as ações de planejamento que visam o desenvolvimento, Souza (2003) entende que esses profissionais também são "planejados", ou seja, formados durante seus cursos ou no ambiente de trabalho. Isso significa dizer que não basta haver "bons planejadores". É preciso saber até que ponto esses profissionais estão ética e tecnicamente preparados ou se contentarão em contribuir ou até legitimar tecnicamente um desenvolvimento entre aspas.

Muitos planejadores profissionais são funcionários a serviço de um aparelho administrativo no qual o que conta são as injunções políticas, os interesses econômicos e não a verdade científica (uma interpretação da realidade condicionada pela racionalidade humana, que tem o consenso da comunidade dos cientistas). A falta de qualificação técnica da maioria dos envolvidos com o turismo no Vale do Ivaí é perceptível em quase todos os municípios. Isso resulta em atraso no desenvolvimento do setor, como no entendimento equivocado do Programa de Regionalização do Turismo e na dificuldade de elaboração de planos e estudos como o Inventário Turístico.

Até entre profissionais de turismo ainda há certa dificuldade em lidar com o planejamento urbano. Yázigy (2011) reflete que o problema profissionalizante do turismólogo se respalda na divisão da atuação do profissional em duas esferas: uma operacional, voltada a prestação de serviços e outra voltada à organização do território vinculada à qualidade ambiental urbana e rural. $\mathrm{O}$ autor aponta que a primeira vertente é dominante nos cursos de turismo, o que implica em uma das dificuldades de se compreender o território e sua ambiência (e, consequentemente seu ordenamento), deixando o planejamento urbano relegado a políticos e atores que geralmente não dialogam com os interesses do desenvolvimento regional.

Sobre desenvolvimento, Souza (2002) indica que a literatura científica sobre o desenvolvimento não tem dedicado uma atenção à altura da importância do turismo. As razões para isso não são muito claras, existindo algumas hipóteses: talvez pelo fato de o turismo de massa ser um fenômeno relativamente recente, pós-Segunda Guerra Mundial; 
talvez por não ter a mesma importância para os países, regiões e municípios, ou ainda porque o turismo frequentemente está associado ao lazer e ao descanso, não sendo visto, embora isso pareça absurdo, como um assunto sério.

Desse modo, o turismo, diante de toda sua complexidade e dos impactos positivos e negativos importantes sobre as relações sociais e o ambiente, merece uma reflexão teórica que dê conta de compreender as especificidades locais sobre seu desenvolvimento. O turismo pode gerar benefícios econômicos em níveis local, regional e nacional, porém esses benefícios devem chegar à população, principalmente às pessoas mais empobrecidas. Cabe, portanto, ao poder público articular os diferentes atores, direcionar a política de turismo de uma localidade, buscando, por meio de parcerias com os segmentos do setor público e privado, os investimentos e formas de comercialização dos atrativos turísticos (ROSE, 2002).

Diante disso, em conformidade com a perspectiva de Silva, Mantovaneli Júnior e Sampaio (2014), entende-se que o desenvolvimento (assim como o turismo) seja concebido em uma visão descentralizada, na qual as características locais de cada comunidade sejam contempladas e valorizadas. Assim, o planejamento deve acontecer de forma dinâmica e sistemática, levando em consideração as mudanças sócio-espaciais que, muitas vezes, perpassam as fronteiras administrativas delimitadas entre os municípios. Deve, portanto, buscar conciliar os interesses dos diferentes atores em prol de um desenvolvimento que possibilite o crescimento ordenado da atividade turística.

Ao abordar o caso de Lunardelli é importante que se tenha claro o conceito de turismo religioso. Segundo o Ministério do Turismo, Brasil (2010, p. 19), pode-se compreender o turismo religioso como uma atividade que tem por finalidade a busca espiritual e da prática religiosa "[...] em espaços e eventos relacionados às religiões institucionalizadas, independentemente da origem étnica ou do credo”. Esse segmento está relacionado à participação em atividades como peregrinações e romarias; roteiros de cunho religioso; retiros espirituais, dentre outros. De acordo com Steil (2003) as categorias peregrinação, romaria e turismo religioso aparecem como sendo sinônimos configurando um universo extenso de práticas sociais. Isso exige o reconhecimento dos diferentes conceitos para uma análise crítica e é de se concordar que: 
[...] essas categorias estabelecem uma relação particular com a realidade a que se referem e com os grupos que as utilizam para denominar suas práticas. Os usos que se fazem desse vocabulário específico denotam, portanto, filiações ideológicas, posições hierárquicas e visões de mundo diversificadas dentro de um campo heterogêneo de práticas sociais e crenças religiosas que compõem a sociedade local e o catolicismo brasileiro (STEIL, 2003, p. 30).

As peregrinações em sua raiz epistemológica estão relacionadas ao estrangeiro que percorre caminhos por terras desconhecidas e inóspitas, adquirindo um traço de heroísmo. Também aparece associado a ideia de um caminho ao encontro do "outro", físico ou espiritual num processo de transformação extraordinária que atinge os peregrinos. Na pósmodernidade religiosa contemporânea é que "associa à experiência interior de um caminho a ser percorrido por cada indivíduo na direção do seu verdadeiro “eu”. Os termos peregrinações são usados geralmente para designar jornadas de longa distância para os santuários mais importantes. Já os deslocamentos mais curtos, que envolvem uma participação comunitária e combinam aspectos festivos e devocionais, são chamados de romarias (STEIL, 2003).

Esse é o conceito que melhor se aplica a realidade de Lunardelli, já que a maior parte dos romeiros ou visitantes tem origem em municípios no próprio Paraná. Essas excursões geralmente são organizadas por um representante ligado às atividades da igreja, atuando com uma espécie de guia de turismo e geralmente não pernoitam com o grupo no local.

O turismo religioso remete a uma estrutura de significados que se afirma de fora para dentro do campo religioso, sendo usado preferencialmente em contextos políticoadministrativos. O que diferencia o turismo da peregrinação ou romaria está no grau de imersão e de externalidade que cada uma dessas experiências pode proporcionar. As peregrinações e as romarias estão mais ligadas à vivência religiosa de imersão no sagrado, o turismo adjetivado como religioso está mais associado ao espetáculo, como em uma festa religiosa (STEIL, 2003). É fato que locais de culto e manifestações religiosas, eventos de cunho místico-espiritual atraem turistas, romeiros e fiéis, que vão aos mesmos lugares e festas. Dessa forma, nem toda viagem é turismo e vice-versa.

A condição de "mercantilização" dos lugares e da religião, com seu aparato de festas e tradições populares, ou seja, a de torná-los desejáveis comercializáveis, está na confecção de imagens. E é aí, no imaginário veiculado pelas mídias e em interação com o fluxo de visitantes/turistas, que turismo e religião vão encontrar seu ponto de convergência e o tecido no qual vão estar alinhavados pelo consumo. A religião torna-se espetáculo e performance, não só pelo olhar 
do turista, mas pelo próprio olhar do adepto, à medida que as modernas transformações culturais vão impactando a maneira como os fiéis manifestam e vivem suas religiões (SILVEIRA, 2007, p. 46).

Silveira (2007) aponta as principais possibilidades de negócio em relação ao aproveitamento turístico da religião por atividades socioeconômicas envolvidas no turismo religioso, tais como: agências de viagem de turismo religioso; agências de viagem em geral; transporte aéreo e rodoviário; sistemas de hospedagem, incluindo casas de aluguel para temporada; artesanato de artigos religiosos, indústrias de itens religiosos, comércio local em geral; serviços de apoio (aluguel de carros, diversão). A seguir será apresentado como se configura o turismo religioso em Lunardelli.

\section{O TURISMO RELIGIOSO NO MUNICIPIO DE LUNARDELLI}

Lunardelli pertence a uma das 14 regiões turísticas do Paraná e a Instância de Governança Regional responsável pela operacionalização do Programa de Regionalização do Turismo (PRT) na região é a Associação dos Municípios do Vale do Ivaí (AMUVITUR). Conforme a última versão do Mapa do Turismo Brasileiro, lançado em 2019 o município de Lunardelli apesar de ter fluxo de turistas, não possui quantidade significativa de hospedagem e desse modo está classificado na categoria D. Observa-se um avanço de categoria de E para D de 2018 para 2019.

Mesmo assim, para o Ministério do Turismo, isso significa que é um município ainda sem expressão turística, apesar de ter o maior fluxo de visitantes do Vale do Ivaí. Estar nessa categoria limita pleitear alguns recursos financeiros, o que é um problema, pois o turismo religioso é um setor econômico importante de geração de renda para o município e precisa de investimentos. Lunardelli não é um município que foi projetado para ser um destino turístico, ou seja, o turismo foi se desenvolvendo sem planejamento.

O secretário municipal de turismo estima que Lunardelli recebe entre oito a dez romarias aos domingos, totalizando entre 100 a 250 mil visitantes durante o ano em decorrência do Santuário Santa Rita de Cássia. Isso gera vários impactos socioeconômicos e ambientais tanto positivos como negativos. Entre os impactos negativos destacam-se o aumento do fluxo de visitantes por meio de carros e ônibus na área urbana, falta de espaço para a ampliação do Santuário; aumento de resíduos sólidos e trabalho informal. Quanto aos impactos positivos ressalta-se um incremento na 
economia local com a criação de novos negócios como hotéis e restaurantes; geração de postos de trabalho e renda para os moradores locais.

Entende-se com isso a necessidade do planejamento do turismo para repensar e evitar os problemas, melhorar e criar ações que resultem no desenvolvimento sustentável da atividade. Portanto, é urgente a elaboração de estudos formais para entender melhor a atividade.

\subsection{LUNARDELLI: CARACTERÍSTICAS GERAIS E O TURISMO RELIGIOSO NO MUNICÍPIO}

Lunardelli é um dos 26 municípios da região do Vale do Ivaí representado pela Associação dos Municípios do Vale do Ivaí (AMUVI), composta por: Apucarana, Arapuã, Ariranha do Ivaí, Bom Sucesso, Borrazópolis, Califórnia, Cambira, Cruzmaltina, Faxinal, Godoy Moreira, Grandes Rios, Ivaiporã, Jandaia do Sul, Jardim Alegre, Kaloré, Lidianópolis, Lunardelli, Marilândia do Sul, Marumbi, Mauá da Serra, Novo Itacolomi, Rio Bom, Rio Branco do Ivaí, Rosário do Ivaí, São João do Ivaí e São Pedro do Ivaí como apresentado na Figura 1.

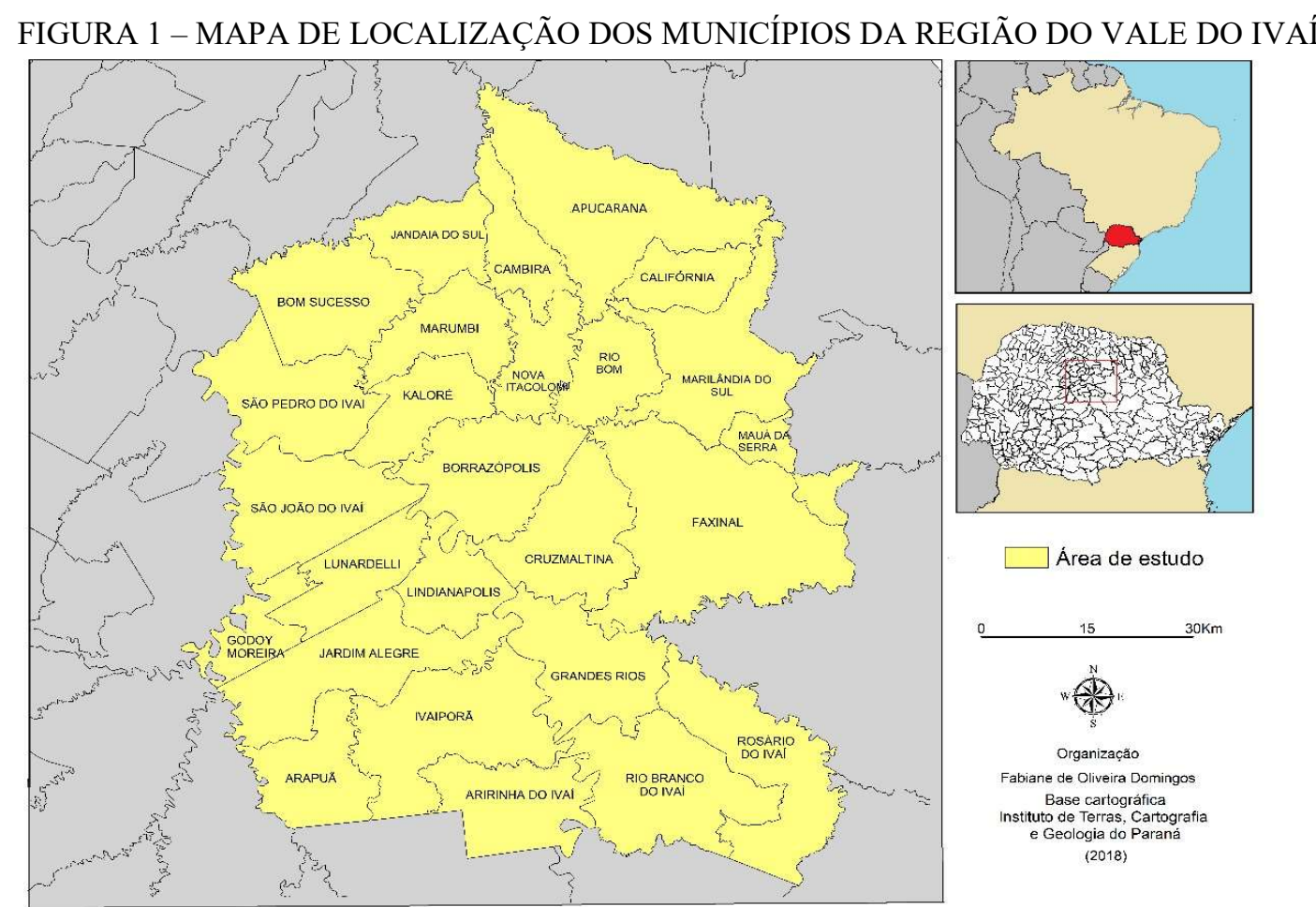

FONTE: DOMINGOS (2018). ADAPTADO DE INSTITUTO DE TERRAS, CARTOGRAFIA E GEOLOGIA DO PARANÁ - ITCG (2018). 
Segundo dados do Instituto Paranaense de Desenvolvimento Econômico e Social (IPARDES, 2018), o município foi instalado em 1983, possuindo 98,929 quilômetros quadrados. Conta com uma população estimada de 4.794 pessoas em 2019 (IBGE, 2020). O IDH é de 0,690, considerado abaixo da média brasileira e do Paraná. Das 2.596 pessoas ocupadas, 75 trabalham com alojamento e alimentação. Possui duas bibliotecas como equipamentos culturais e é produtor de alfafa, café, soja, milho e trigo. No aspecto natural, o município conta com a maior Reserva Particular do Patrimônio Natural (RPPN) da região (IPARDES, 2018).

Segundo Novais (2019), no dia $1^{\circ}$ de julho de 1963 foi realizada a primeira missa pelo padre Emílio Collec, pároco da Paróquia São João Batista de São João do Ivaí. Na ocasião surgiu o primeiro líder religioso em Lunardelli, que teve expressiva participação nos movimentos religiosos, o senhor João Costamagna. Desse modo, o marco histórico da religiosidade no município se deu no ano de 1963, quando ainda era distrito, época em que não tinha um(a) padroeiro(a). Maria Pinto Momente e Armando Momente doaram uma imagem de Santa Rita de Cássia proveniente de São Paulo para a futura Paróquia de Lunardelli. Moradores da fazenda Mundo Novo também foram responsáveis pelo levantamento do cruzeiro na praça, local que em 1969 se tornaria a sede da paróquia Santa Rita de Cássia, conhecida como a santa dos desesperados e das causas impossíveis na religião cristã.

No ano de 1994, o município passava por dificuldades financeiras decorrentes de problemas na agricultura ocasionando a emigração da população e por essa razão, a comunidade solicitou a realização de uma novena. Nesse mesmo ano, no dia 22 de janeiro, um grupo de seminaristas vindos para uma missão, a fim de visitar famílias do município, decidem fazer a novena que teve a participação de 1500 pessoas. Assim, neste mesmo dia, a cada mês, às 15 horas foi instituída uma novena em homenagem a Santa Rita de Cássia (ROSSI; CAETANO; JANOLIO, 2005).

No ano de 1995, a comunidade decidiu construir uma Gruta ao lado do santuário, tornando-se mais um atrativo aos visitantes e ao seu lado uma fonte com água potável. Uma das imagens da Santa foi colocada na gruta onde permanece até hoje, entre flores e velas. Ao contrário da Figura 2, atualmente o espaço onde localiza-se a gruta possui cobertura, para melhor conforto dos visitantes. 
FIGURA 2 - IMAGEM DE FIÉIS NA GRUTA DE SANTA RITA DE CÁSSIA, EM LUNARDELLI

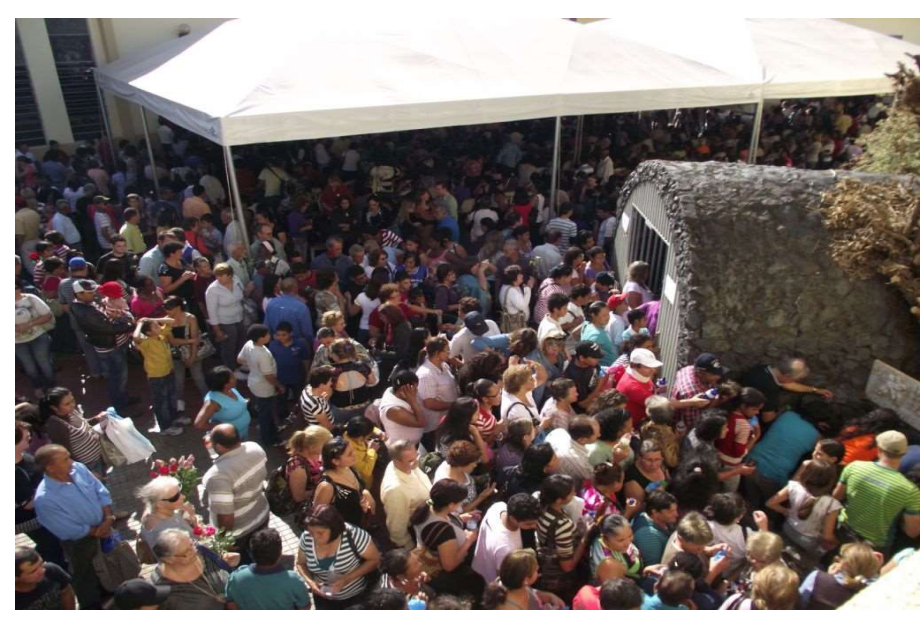

FONTE: Francisco Izidoro (2020).

Em 1997, o padre João viajou a Europa e visitou o santuário onde está exposto o corpo original de Santa Rita. Posteriormente, foi criada uma réplica exposta no interior do santuário em Lunardelli. Em 1997, por meio do projeto de Lei n. 637/99, a Assembleia Legislativa do Paraná autorizou o poder executivo a instituir o município como polo do turismo religioso, sendo hoje o segundo principal destino turístico do Paraná voltado para o turismo religioso (ROSSI; CAETANO; JANOLIO, 2005).

Foi somente em março de 2006 que o Conselho de presbíteros de Apucarana, com o Bispo Dom Celso Antônio, decidiu conceder o título de Santuário a Paróquia. No dia 22 de maio desse mesmo ano foi realizada uma festa em comemoração com a presença de mais de 20.000 pessoas oriundas de outros municípios e estados (NOVAIS, 2019).

Em julho de 2018, o secretário de esporte e turismo do Paraná confirmou R\$ 800 mil de recursos financeiros para construção de um espaço multiuso na Praça Comendador Geremias Lunardelli. Essa obra projetada pela prefeitura, teve como objetivo melhorar os serviços aos romeiros que visitam o santuário. Também houve recurso direcionado para obras como a troca de pisos e bancos, melhora da iluminação e paisagismo. Um investimento de R 225 mil, recursos oriundos de emenda parlamentar (MALDONADO, 2018).

O santuário de Santa Rita de Cássia também foi reformado, ampliando sua capacidade de recebimento para 2600 visitantes. Essas alterações se deram em 2014 em função da demanda crescente de fiéis que visitavam o local. Isso indica que o turismo necessita de planejamento constante para que a estrutura do município consiga comportar a quantidade de visitantes. Ao mesmo tempo é preciso que a população esteja ciente e de 
acordo com essas novas mudanças para que não haja uma descaracterização cultural e perda de referenciais identitários. Nas Figuras 3 e 4 é possível ver o antes e depois da reforma no Santuário.

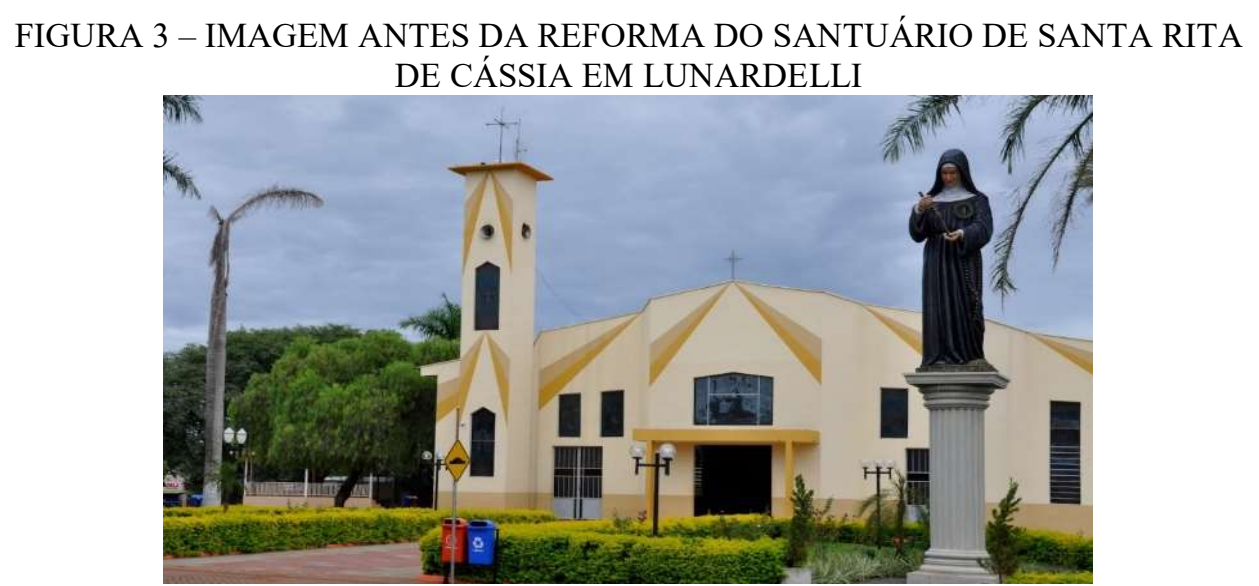

FONTE: Santuário (2019).

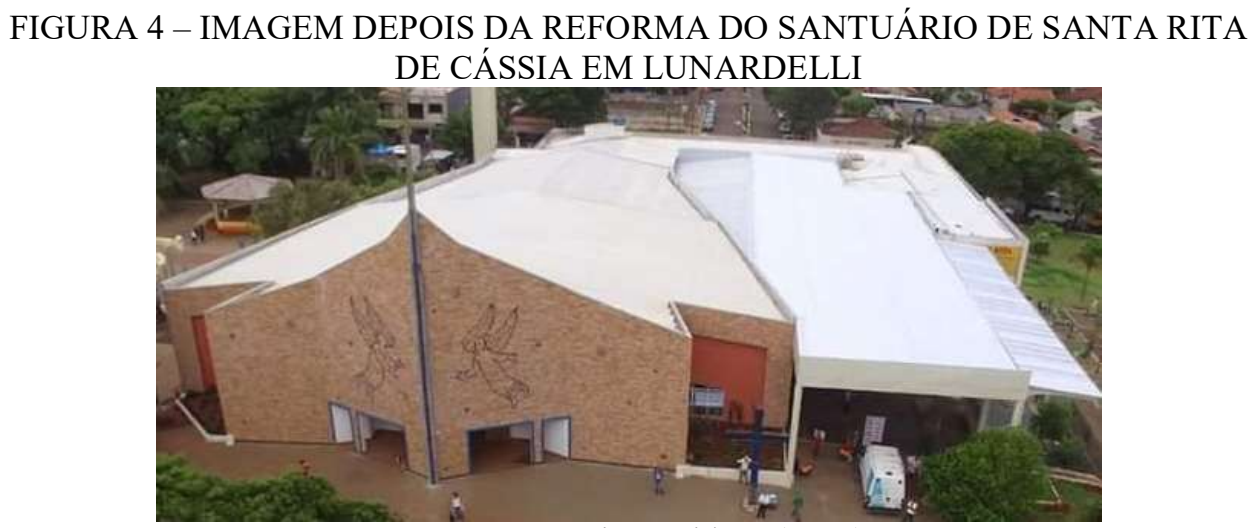

FONTE: Francisco Izidoro (2020).

Para o ano de 2019 foi elaborado pelo governo municipal um plano de ação para o turismo com as seguintes propostas: consultoria jurídica para reformulação da lei municipal de turismo; inventário de oferta turística; Plano Municipal de Turismo; Plano de Turismo de Desenvolvimento Socioeconômico; Plano de Marketing e Estudo de demanda turística. Dessas propostas de ações, verificou-se que somente o Inventário da Oferta Turística está em finalização pelo curso de Turismo e Negócios da UNESPAR campus Apucarana a ser entregue no primeiro semestre de 2020.

De acordo com as entrevistas realizadas, verificou-se que em Lunardelli há alguns problemas decorrentes da atividade turística, como a falta da produção associada ao turismo, tornando-se uma preocupação para o setor público. Grande parte dos produtos 
vendidos na feira que acontece na praça do santuário não é produzida no município. Isso precisa ser revertido na criação de um plano de desenvolvimento socioeconômico que identifique o que pode ser feito para gerar maior renda e trabalho para a população local e que tenha uma identidade cultural. A prefeitura faz parcerias com várias instituições como o Serviço Brasileiro de Apoio às Micro e Pequenas Empresas (Sebrae) e Instituto Paranaense de Assistência Técnica e Extensão Rural (Emater) que desenvolvem ações nesse sentido.

Durante visita técnica foi constatado que a maioria das peças sacras vendidas na feira não são de Santa Rita, ou seja, são de outros santos(as) e não fabricadas em Lunardelli. Algumas barracas não vendem produtos relacionados a temática religiosa, sendo difícil, por exemplo, encontrar vestuário como camisetas com a imagem de Santa Rita de Cássia.

Mas já é possível verificar que alguns artesãos locais estão começando a desenvolver peças exclusivas para venda, como santas revestidas de miçangas tipo pérolas e outras fabricadas com cerâmica. Uma barraca comercializa geleias, compotas e embutidos produzidos em uma propriedade rural.

Também há uma preocupação por parte da prefeitura em formalizar esses vendedores para que dessa maneira possam contribuir com impostos para o município. Esse mesmo trabalho está acontecendo com os empreendimentos de alimentação como pequenos restaurantes e padarias, os quais trabalhavam na informalidade.

Outra situação observada é falta de uma infraestrutura adequada para a realização da feira. Atualmente ocorre na praça onde se localiza o Santuário, porém é ao ar livre e nos dias de sol intenso ou chuva causam incômodos aos visitantes, prejudicando o comércio. Já existe um projeto para alocar os visitantes futuramente em um ambiente protegido.

É perceptível a movimentação econômica no comércio local em decorrência do turismo religioso, mas conforme exposto pelo secretário municipal de turismo, é urgente e necessária a realização de pesquisas que quantifiquem e analisem esses dados. É preciso compreender os reais impactos da atividade na economia local e regional. Para tanto, estudos podem auxiliar a prefeitura na captação de recursos e investimentos financeiros públicos e privados. 
O setor público de Lunardelli compreende a importância econômica, social e ambiental do turismo e se preocupa com o direcionamento da atividade. Os gestores públicos entendem que é necessário e urgente o apoio de outras instituições por meio de parcerias como a que ocorreu em 2019 com o curso de Turismo e Negócios da UNESPAR.

Também há a necessidade de uma participação efetiva da população local para que o turismo não seja uma atividade excludente e massiva. É válido ressaltar que não são todas as intervenções do turismo que se traduzem necessariamente na agressão ou na degradação do meio ambiente natural ou cultural. Toda transformação econômica ou social, independentemente de sua origem, pode provocar modificações na relação ser humano com seu espaço. Nesse sentido, é preciso ter cautela ao responsabilizar o turismo por determinadas agressões ao meio em que está inserido, pois existem muitas vantagens na atividade que devem ser observadas.

Os turistas consomem artesanatos e outros produtos, em restaurantes fazem circular renda nas economias local, nacional e internacional. Turistas dormem em hospedarias, hotéis e pousadas. Verifica-se uma gama de negócios a serem explorados. Em Lunardelli de modo a descentralizar o turismo da área central, além do Santuário e seu entorno foi inaugurada em 2019, a 'Rota das Capelas'. Em entrevista ao jornal Paranacentro, Francisco Izidoro explica que as capelas foram construídas no espaço rural pelos agricultores locais e acredita que essa rota pode auxiliar o município na conservação do patrimônio histórico local e para da região do Vale do Ivaí (ANDREIS, 2019).

Como exemplo de visitação a Lunaderli, em janeiro de 2020 um grupo de oitenta e quatro pessoas da associação Nossa Senhora dos Impossíveis de Curitiba e comunidades de Nova Tebas no Paraná percorreram 66 quilômetros entre Nova Tebas e Lunardelli. Em Lunardelli perfizeram a Rota das Capelas visitando a Capela Nossa Senhora de Fátima, Capela Santa Ana, Capela São José e Capela Cristo Rei das comunidades rurais do município. O percurso finalizou no Santuário Santa Rita de Cássia. A Figura 5 mostra o grupo em uma das capelas. 


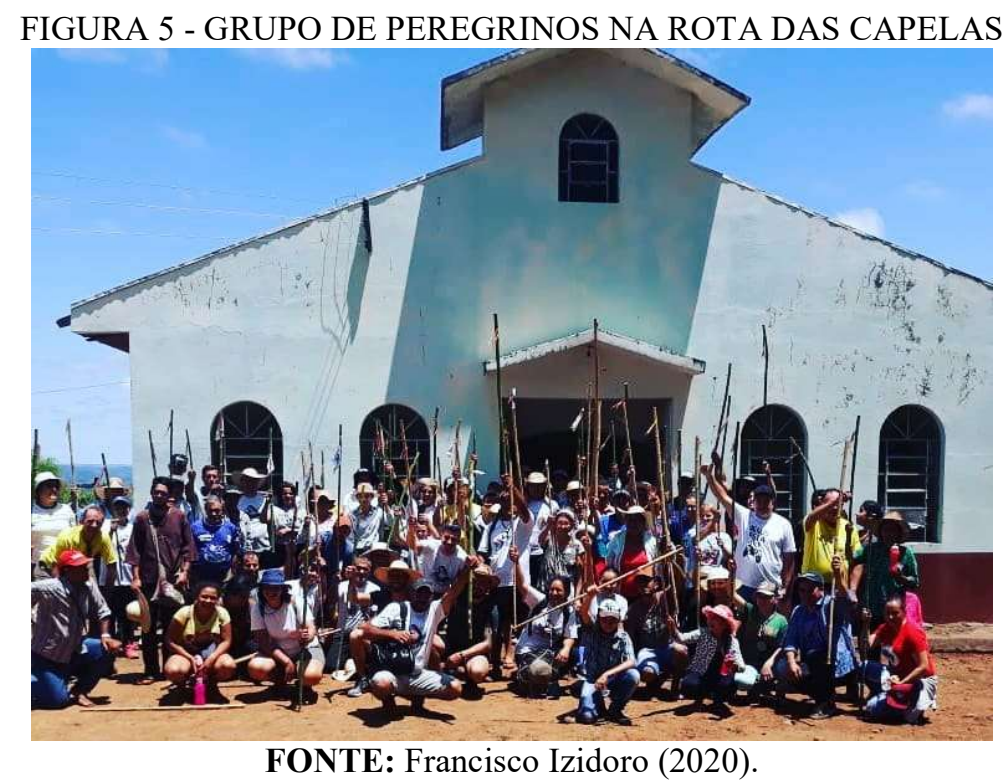

O turismo religioso é uma realidade em Lunardelli, porém, o município, que não foi projetado para ser um destino turístico, padece de problemas relacionados ao fluxo crescente de visitantes no Santuário de Santa Rita Cássia. Os maiores problemas se devem ao planejamento urbano, já que o município, por ser pequeno, tem dificuldades em comportar o fluxo crescente de visitantes pela geração de impactos sócio-espaciais.

O Santuário realiza constantemente obras de infraestrutura como a ampliação do número de banheiros, da caixa de água, entre outras. Já a prefeitura apesar de ser laica, entende que a atividade turística movimenta a economia e por isso, procura apoiar a atividade com a realização de projetos. As obras se dão principalmente em relação a infraestrutura básica como na ampliação do sistema de tratamento de água e esgoto, melhorias na praça central em que se localiza o Santuário, coleta e tratamento de resíduos sólidos e apoio aos micro e pequenos empresários, dentre outras ações.

Em 2020 por exemplo, foi aprovada a construção de portais turísticos em Lunardelli, com recursos a serem liberados pelo Ministério do Turismo por emenda parlamentar de um deputado federal. A empresa que venceu a licitação vai executar a obra por R\$ 600 mil. O prefeito Reinaldo Grola afirma que essa obra vai “dar uma identidade para o município e ter mais uma atração para o turismo de Lunaredelli” (TNOnline, 2020). Esse projeto segue a tendência de alguns municípios do Vale do Ivaí que já possuem portais turísticos como São Pedro do Ivaí e Califórnia com esculturas religiosas católicas. Apesar de ser uma obra controvérsia pelo fato de pouco ou nada contribuir com o aumento 
de visitantes, esses portais turísticos adquirem um sentido para além do religioso e podem se configurar como patrimônios culturais, quando tratados a partir de sua especificidade.

O turismo religioso em Lunardelli é uma atividade que gera emprego e renda local, mas que precisa ser ampliado por meio de projetos. Ele necessita melhorar a qualidade da infraestrutura e dos serviços e estimular novos negócios na área de hospedagem, artesanatos e/ou souvenirs, gastronomia, eventos, entre outros.

\section{CONSIDERAÇÕES FINAIS}

O presente estudo teve como objetivo analisar os principais desafios do planejamento do turismo religioso em Lunardelli. Os resultados demonstraram que essa atividade que iniciou na década de 1990, ainda está se estruturando e apresenta alguns problemas relacionados ao aumento do número de visitantes.

Durante a pesquisa foram identificados vários atrativos e potencialidades para o turismo de cunho religioso nos municípios que compõem o Vale do Ivaí. A maioria desses atrativos corresponde a monumentos culturais, templos religiosos e atividades com temas religiosos como caminhadas na natureza, propostas de rotas, festas e outros. A religião predominante e que exerce influência na cultura local devido ao processo de colonização é a católica. Lunardelli é, portanto, o principal destino de turismo religioso na região do Vale do Ivaí pelo fluxo de visitantes, podendo ser o indutor de novas rotas e circuitos religiosos na região.

A atuação dos responsáveis pelo santuário atualmente é de divulgação do mesmo, a fim de atrair cada vez mais visitantes e, portanto, o município deve se preparar para que a atividade não traga ainda mais transtornos para a comunidade local. Nesse sentido, compreende-se a necessidade da participação da comunidade local nesse processo, por meio do Conselho Municipal de Turismo e em outros momentos, como audiências públicas e reuniões na Câmara de vereadores a fim de discutir os melhores rumos para o turismo no município.

O turismo religioso em Lunardelli deve ser pautado no conceito de desenvolvimento de base local contribuindo assim para o desenvolvimento da região do Vale do Ivaí. A parceria entre as instituições envolvidas com o planejamento do turismo na região é fundamental para fortalecer esse processo. É necessária a realização de 
pesquisas mais aprofundadas com análise dos dados, pois, os registros são apenas informais sendo disponibilizados pelo próprio Santuário. Também é necessário um estudo da demanda turística para explicar o comportamento e o perfil do visitante antes, durante e depois da viagem. Dessa forma será possível compreender de forma científica a dinâmica do turismo religioso em Lunardelli e assim formular e implementar políticas públicas efetivas na melhor do IDH da região, na redução da emigração da população com a ampliação de trabalho população economicamente ativa, um dos principais problemas do Vale do Ivaí.

Diante dos resultados esse artigo tem como implicação prática a demonstração para os agentes públicos e privados que apensar dos inúmeros desafios para o turismo se desenvolver em Lunardelli, há um leque de novas possibilidades de desenvolvimento regional e criação de negócios por meio de micro e pequenas empresas de turismo e utilização de novos atrativos, tanto para o município como para a região do Vale do Ivaí.

A pesquisa apresentou limitações em relação a utilização de métodos de pesquisas, isso pode ser resolvido por meio de novas abordagens com pesquisas que envolvam o estudo e análise dos impactos da atividade turística na economia, sobre a qualidade dos empreendimentos e atrativos turísticos, sobre a demanda turística, levanto histórico/ cultural do município, entre outros. São necessários estudos mais específicos sobre os visitantes, sobre a economia e sobre os empreendimentos e atrativos turísticos existentes. A amostra dos entrevistados também pode ser maior com a participação de outros gestores públicos e privados. Todavia, esse artigo contribui para futuras pesquisas auxiliando pesquisadores de turismo, principalmente discentes e docentes que atuam na região do Vale do Ivaí, pois são poucas as pesquisas científicas sobre o turismo na região.

\section{REFERÊNCIAS}

ANDREIS, A. Rota das capelas acontecerá em Lunardelli. Paraná Centro, Ivaiporã, 02 nov. 2019. Disponível em: https://jornal.paranacentro.com.br/noticia/29743/rotadas-capelas-acontecera-em-lunardelli. Acesso em: 3 fev. 2020.

BINFARÉ, P. W.; CASTRO, C. T.; SILVA, M. V.; GAlVÃO, P. L.; COSTA, S. P. Planejamento turístico: aspectos teóricos e conceituais e suas relações com o conceito de turismo. Revista de Turismo Contemporâneo, v. 4, 15 abr. 2016. Disponível em: https://periodicos.ufrn.br/turismocontemporaneo/article/view/6042. Acesso em: 26 jan. 2020 . 
BRASIL. Ministério do Turismo. Turismo Cultural: orientações básicas. Brasília: Ministério do Turismo, 2010.

DOMINGOS, F. de O. A política de regionalização do turismo no Vale do Ivaí: Uma análise a partir do conceito de desenvolvimento regional. Londrina, 2018. Tese (Doutorado em Geografia) - Universidade Estadual de Londrina, Londrina, 2018.

FAISSOL, S. Planejamento e Geografia: Reflexões conceituais e exemplos da experiência brasileira. Geográfica, n. 109, p. 167-198, jan./jun. 1989.

GIL, A. C. Métodos e técnicas de pesquisa social. São Paulo: Atlas, 2009.

FRANCISCO IZIDORO. Grupo de Peregrinos. Disponível em:

https://www.facebook.com/francisco.izidoro.9. Acesso em: 03 fev. 2020.

INSTITUTO BRASILEIRO DE GEOGRAFIA E ESTATISTICA (IBGE). Cidades. Disponível em: https://cidades.ibge.gov.br/brasil/pr/lunardelli/panorama. Acesso em: 28 mar. 2020.

INSTITUTO PARANAENSE DE DESENVOLVIMENTO ECONÔMICO E SOCIAL (IPARDES). Caderno Estatístico - Município Lunardelli, 2018. Disponível em: http://www.ipardes.gov.br/cadernos/MontaCadPdf1.php?Municipio=86935. Acesso em: 20 jan. 2020.

INSTITUTO DE TERRAS, CARTOGRAFIA E GEOLOGIA DO PARANÁ. Cartas Topográficas. (2018). Disponível em:

http://www.itcg.pr.gov.br/modules/conteudo/conteudo.php? conteudo=51. Acesso em: jan. 2018.

LUNARDELLI vai ganhar portais turísticos, processo de licitação já foi concluído. TNOnline, 29 fev. 2020. Região. Disponível em:

https://tnonline.uol.com.br/noticias/regiao/32,489740,29,02, lunardelli-vai-ganharportais-turisticos-processo-de-licitacao-ja-foi-concluido. Acesso em: 29 mar. 2020.

MALDONADO, I. Turismo de Lunardelli garante recursos. TNOnline, 04 jul. 2018. Região. Disponível em:

https://tnonline.uol.com.br/noticias/regiao/32,468001,04,07,turismo-delunardelligarante-recursos. Acesso em: 21 nov. 2018.

NOVAIS, A. Lunardelli: a história do município. Lunardelli: Paraná Centro, 2019.

ROSE, A. T. de. Turismo: planejamento e marketing. Barueri: Manole, 2002.

ROSSI, L. A. S.; CAETANO L.; JANOLIO, K. M. E. Desenvolvimento da cidade de Lunardelli através do turismo religioso; existe sustentabilidade? Ou basta ter fé?

Iniciação Científica CESUMAR, v. 7, n. 2, p. 185-196 jul./dez. 2005.

SANTUÁRIO de Santa Rita de Cássia. Gruta Santa Rita. 2019. Disponível em: 
https://www.santaritalunardelli.com.br/gruta-santa-rita/. Acesso em: 01 maio 2019.

SILVA, L. F. da; MANTOVANELI JÚNIOR, O.; SAMPAIO, C. A. C.

Desenvolvimento turístico regional: governança e territorialidade no caso da oktoberfest Blumenau (Santa Catarina, Brasil). Turismo e Sociedade. v. 7, n.1, p. 156-173, 2014. Disponível em:

https://revistas.ufpr.br/turismo/article/view/37147/22852. Acesso em: 29 mar. 2020.

SILVEIRA, E. J. S. Turismo Religioso no Brasil: uma perspectiva local e global. Turismo em Análise, v. 18, n. 1, p. 33-51, 2007. Disponível em: http://www.revistas.usp.br/rta/article/view/62606/65394. Acesso em: 29 mar. 2020.

SOUZA, M. J. L. de. Como pode o turismo contribuir para o desenvolvimento local? In: RODRIGUES, A. B. (Org.) Turismo e desenvolvimento local. São Paulo: Hucitec, 2002. p. 17-22.

ABC do desenvolvimento urbano. Rio de Janeiro: Bertrand Brasil, 2003.

STEIL, C. A. Peregrinação, romaria e turismo religioso: raízes etimológicas e interpretações antropológicas. In: ABUMANSSUR, E. S. Turismo religioso: ensaios antropológicos sobre religião e turismo. Campinas: Papirus, 2003. p. 29-51.

TRENTIN, F.; FRATUCCI, A. C. Política nacional de turismo no Brasil: da municipalização à regionalização. In: International Conferece on Tourism Management Studies, 2011, Algarve, Portugal. Book of proceedings. Algarve, Portugal: Escola Superior de Gestão, Hotelaria e Turismo, 2011. v. 1. p. 845-855.

YÁZIGY, E. Por um novo horizonte profissional do turismólogo. Rosa dos Ventos. Caxias do Sul, v. 3, n.3 p. 424-432, dez. 2011. Disponível em: http://www.ucs.br/etc/revistas/index.php/rosadosventos/article/view/1289. Acesso em: 28 jan. 2020.

Recebido em: 20-10-2019

Aprovado em: 03-04-2020 